\title{
FORMATION OF TETERAVALENT CERIUM PHOSPHATE IN SUSPENSION AND THEIR POWDER PROPERTIES
}

\author{
Hiroaki Onoda* and Ayumi Ikawa \\ (*Corresponding author: onoda@kpu.ac.jp) \\ Department of Informatics and Environmental Sciences, Faculty of Life and Environmental Sciences, Kyoto \\ Prefectural University, 1-5, Shimogamo Nakaragi-cyo, Sakyo-ku, Kyoto 606-8522, Japan
}

Keywords: Cerium phosphate, Chemical synthesis, Specific surface area, Adsorbent

\begin{abstract}
The preparation process was studied to obtain phosphate material with large specific surface area. Tetravalent cerium phosphate was prepared from ammonium cerium nitrate and phosphoric acid. In this system, as a solvent, water and ethanol were used, the solvent volume was limited, propionic acid and $n$-butylamine were added. These preparation conditions had much influence on the ratio of cerium/phosphorus. By the addition of $n$-butylamine, specific surface area of cerium phosphate became large. The adsorption ratio of basic stinking gas increased with the addition of propionic acid and $n$-butylamine in suspension condition.
\end{abstract}

(Received December 27, 2010; Accepted March 30, 2011)

\section{INTRODUCTION}

Phosphates have been used for ceramic materials, catalysts, adsorbent, fluorescent materials, dielectric substances, metal surface treatment, fertilizer, detergents, food additives, fuel cells, pigments, and other items. The catalytic and adsorptive properties of phosphates were affected from specific surface area ${ }^{1-3}$. To improve the functional properties, porous phosphate, which had large specific surface area, was prepared in previous reports ${ }^{4,5}$. The additives had some possibility to obtain large specific surface area in the fields of synthesis of inorganic materials ${ }^{6-8}$. Aluminum phosphates containing urea were obtained in aqueous solution ${ }^{9}$. By the decomposition of urea, this aluminum phosphate became porous material. The specific surface area of aluminum phosphate improved from 124 to $153 \mathrm{~m}^{2} \mathrm{~g}^{-1}$ in this method.

This method indicated a weak point that the remained urea in the phosphate particles decreased the amount of acidic sites on surface of materials. The acidic solid state materials has the possibility to be used as adsorbent for basic malodorous gases. The adsorption ability of basic stinking gas became weak by the addition of urea.

Therefore, other additives were expected to improve the specific surface area and the removal ability of such gases ${ }^{10,11}$. Urea has basic sites at both ends. As new additives on preparation of phosphate material, malonic acid has acidic sites at both ends and propionic acid has acidic site at one-sided acidic site. Glycine has acidic site and basic site at each side, and $n$-butylamine has one-sided basic site. These additives are studied to prepare porous cerium phosphate. Rare earth cations are generally trivalent state, however some cations are stable in other valence state. Cerium cation forms stable tetravalent compounds ${ }^{12}$. These compounds are expected to have different properties with other rare earth compounds. In previous work ${ }^{13}$, the included ratio (additive/phosphorus) was smaller than the ratio of additives in preparation system of tetravalent cerium phosphate. The additives were eluted to the filtered solution. Therefore, the volume of solvent was important factor for that phosphate material contained these additives efficiently.

In this work, cerium (+IV) phosphates were prepared from ammonium cerium nitrate and phosphoric acid solution, with the additives described above. Their properties were studied for design of functional materials.

\section{EXPERIMENTAL}

FIGURE 1 shows preparation process in this work. $2 \mathrm{ml}$ of phosphoric acid $(14 \mathrm{~mol} / \mathrm{l})$ was diluted with $5 \mathrm{ml}$ of water and ethanol. $0.14 \mathrm{~mol} / 1$ of propionic acid or $n$-butylamine was added to this solution. Further, cerium ammonium nitrate, $\left(\mathrm{NH}_{4}\right)_{2} \mathrm{Ce}\left(\mathrm{NO}_{3}\right)_{6}$, was mixed with this solution in a molar ratio of $\mathrm{Ce} / \mathrm{P}=3 / 4$. These mixtures were a 
suspension condition. One sample was synthesized by that this suspension was filtered off and dried. Another sample was prepared by drying all of the suspended solution. The drying temperature was $100^{\circ} \mathrm{C}$ for 20 hours. As exceptions, samples prepared with $n$-butylamine were dried at $200^{\circ} \mathrm{C}$ for 20 hours, because these samples could not be dried at $100^{\circ} \mathrm{C}$. Sample prepared without additives and with filtration was not prepared because the volume of solvent was small.

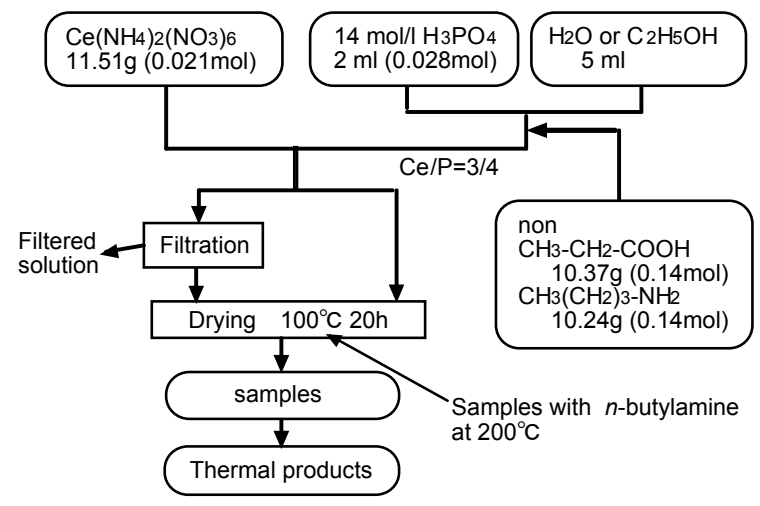

FIGURE 1. Preparation process of tetravalent cerium phosphate.

A part of the precipitates was dissolved in hydrochloric acid solution. The ratios of phosphorus and cerium in the precipitates were also calculated from ICP results of these solutions, using SPS1500VR, Seiko Instruments Inc. The thermal behavior of these materials was analyzed by TG-DTA and XRD. TG and DTA curves were measured with a Shimadzu DTG-60H at a heating rate of $10{ }^{\circ} \mathrm{C} / \mathrm{min}$ under air. XRD patterns were recorded on a Rigaku Denki RINT 1200M X-Ray diffractometer using monochromated $\mathrm{CuK} \alpha$ radiation.

Scanning electron microscopy (SEM) images of cerium phosphates were observed using JGM-5510LV, JEOL Ltd. The particle size distributions of these materials were measured with laser diffraction / scattering particle size distribution HORIBA LA-910. The specific surface area of phosphates was calculated from the amount of nitrogen gas adsorbed at the temperature of liquid nitrogen by BET method with a Belsorp mini from Bel Japan.

The adsorption of trimethylamine gas on phosphates was estimated at room temperature. 0.01 $\mathrm{g}$ of a sample was placed in a gas bag $\left(3000 \mathrm{~cm}^{3}\right)$ of polyethylene, which was then filled with trimethylamine gas (14.4 ppm). The concentration of trimethylamine gas after standing for 10 minutes was determined with a Kitagawa gas detector.

\section{RESULTS AND DISCUSSION}

\section{CHEMICAL COMPOSITION OF OBTAINED PRECIPITATES}

TABLE 1 shows $\mathrm{Ce} / \mathrm{P}$ ratio of precipitate calculated from ICP results. In this work, tetravalent cerium phosphate, $\mathrm{Ce}_{3}\left(\mathrm{PO}_{4}\right)_{4}$, was target material, their $\mathrm{Ce} / \mathrm{P}$ ratio was 0.75 . The $\mathrm{Ce} / \mathrm{P}$ ratio was indicated around 0.75 in samples prepared without additive in spite of kinds of solvents. Samples prepared with propionic acid had high $\mathrm{Ce} / \mathrm{P}$ ratio. The chemical composition was considered to be the mixture of $\mathrm{CePO}_{4}$ and $\left(\mathrm{NH}_{4}\right)_{2} \mathrm{Ce}\left(\mathrm{NO}_{3}\right)_{6}$ from ICP results. On the other hand, the ratio of $\mathrm{Ce} / \mathrm{P}$ in samples prepared with $n$-butylamine was smaller than 0.75. These ICP results devised the formation of $\mathrm{Ce}\left(\mathrm{HPO}_{4}\right)_{2}$ and phosphorus rich compounds. In large amount of water (solvent), precipitates obtained with $n$-butylamine had large ratio of cation/phosphorus ${ }^{10}$. These were caused from the formation of hydroxide.

TABLE $1 \mathrm{Ce} / \mathrm{P}$ ratio of samples from ICP results

\begin{tabular}{cccc}
\hline additive & filtration & \multicolumn{2}{c}{$\mathrm{Ce} / \mathrm{P}$} \\
& & water & ethanol \\
\hline non & - & 0.77 & 0.67 \\
propionic acid & $\circ$ & 1.85 & 2.73 \\
propionic acid & - & 1.43 & 0.90 \\
$n$-butylamine & $\circ$ & 0.54 & 0.47 \\
$n$-butylamine & - & 0.46 & 0.57 \\
\hline
\end{tabular}

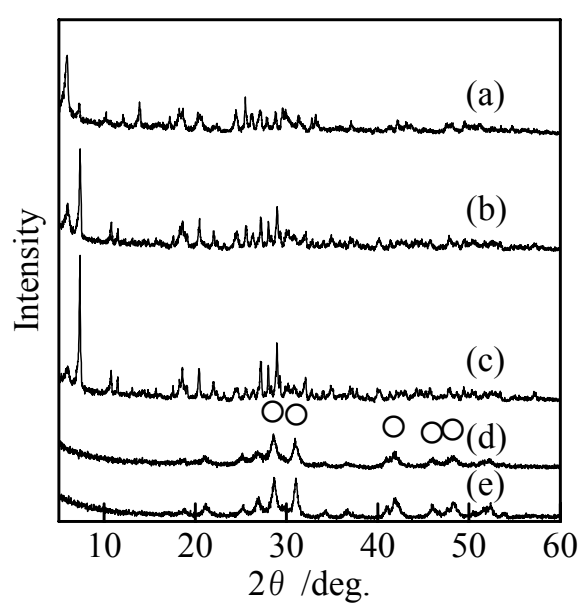

FIGURE 2. XRD patterns of samples obtained in aqueous condition and at $200^{\circ} \mathrm{C}$, (a) no additive, (b) propionic acid, with filtration, (c) propionic acid, without filtration, (d) $n$-butylamine, with filtration, (e) $n$-butylamine, without filtration, $\mathrm{O} ; \mathrm{CePO}_{4}$. 
TABLE 2 XRD patterns of samples prepared in various conditions

\begin{tabular}{|c|c|c|c|c|c|c|c|}
\hline \multirow[t]{2}{*}{ additive } & \multirow[t]{2}{*}{ filtration } & \multicolumn{3}{|c|}{ water } & \multicolumn{3}{|c|}{ ethanol } \\
\hline & & $100^{\circ} \mathrm{C}$ & $200^{\circ} \mathrm{C}$ & $400^{\circ} \mathrm{C}$ & $100^{\circ} \mathrm{C}$ & $200^{\circ} \mathrm{C}$ & $400^{\circ} \mathrm{C}$ \\
\hline non & - & unknown $^{1}$ & unknown $^{3}$ & unknown $^{6}$ & unknown $^{2}$ & unknown $^{4}$ & $\mathrm{CePO} 4$ \\
\hline propionic acid & ○ & unknown $^{1}$ & unknown $^{5}$ & unknown $^{6}$ & unknown $^{1}$ & unknown $^{5}$ & unknown $^{6}$ \\
\hline propionic acid & - & unknown $^{1}$ & unknown $^{5}$ & unknown $^{6}$ & unknown $^{1}$ & unknown $^{5}$ & unknown $^{6}$ \\
\hline$n$-butylamine & ○ & $\mathrm{x}$ & $\mathrm{CePO}_{4}$ & $\mathrm{CePO} 4$ & $\mathrm{x}$ & $\mathrm{CePO}_{4}$ & $\mathrm{CePO}_{4}$ \\
\hline$n$-butylamine & - & $\mathrm{x}$ & $\mathrm{CePO}_{4}$ & $\mathrm{CePO} 4$ & $\mathrm{x}$ & $\mathrm{CePO}_{4}$ & $\mathrm{CePO}_{4}$ \\
\hline
\end{tabular}

Unknown patterns were classified to 6 groups.

The ratio of cation/phosphorus indicate the reverse tendency at samples prepared in small amount of solvent. The filtered samples had larger $\mathrm{Ce} / \mathrm{P}$ ratio than non-filtered samples. The kind of solvent, water and ethanol, was not clear to change the $\mathrm{Ce} / \mathrm{P}$ ratio in precipitates.

FIGURE 2 shows XRD patterns of samples synthesized in water conditions. Samples prepared without additives and with propionic acid indicated unknown peaks. On the other hand, XRD peak pattern of Monazite-type $\mathrm{CePO}_{4}$ was observed in sample prepared with $n$-butylamine (TABLE 2). In large amount of water as a solvent, samples prepared with $n$-butylamine indicated amorphous phase in XRD analyses. The volume of water had influence on the crystalline condition of materials. Furthermore, in ethanol condition, sample prepared without additive indicated XRD peaks of Monazite-type $\mathrm{CePO}_{4}$ in the same with samples prepared with $n$-butylamine.

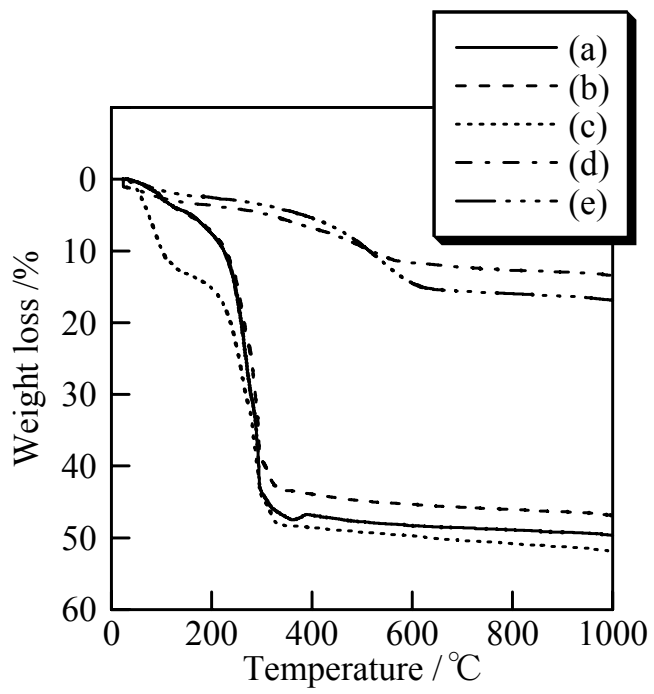

FIGURE 3. TG curves of samples obtained in aqueous condition, (a) no additive, $100{ }^{\circ} \mathrm{C}$, (b) propionic acid, with filtration, $100^{\circ} \mathrm{C}$, (c) propionic acid, without filtration, $100^{\circ} \mathrm{C}$, (d) $n$-butylamine, with filtration, $200{ }^{\circ} \mathrm{C}$, and (e) $n$-butylamine, without filtration, $200^{\circ} \mathrm{C}$.
FIGURE 3 shows TG curves of samples synthesized in water conditions. Samples prepared with propionic acid indicated similar TG curve with sample prepared without additive. The weight loss at about $120^{\circ} \mathrm{C}$ was due to the volatilization of water (Fig.3(c)). The volatilization of ammonia and nitrogen oxide from nitrate anion caused large weight loss at about $260^{\circ} \mathrm{C}$. On the other hand, samples prepared with $n$-butylamine had different TG curves with sample prepared without additive. This phenomenon was not observed at samples prepared in large amount of water as a solvent. Samples prepared with ethanol had similar TG curves with those prepared with water except the scale of weight loss at $120^{\circ} \mathrm{C}$.

FIGURE 4 shows DTA curves of samples synthesized in water conditions. Samples prepared without additive and with propionic acid had some endothermic peaks below $300^{\circ} \mathrm{C}$. The endothermic

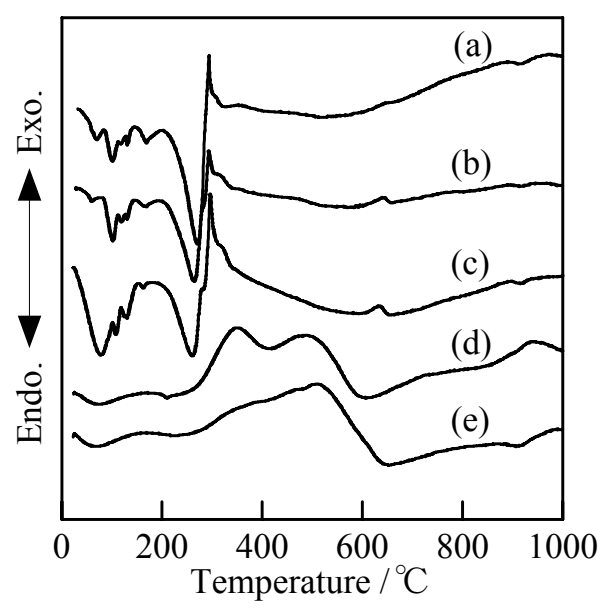

FIGURE 4. DTA curves of samples obtained in aqueous condition, (a) no additive, $100{ }^{\circ} \mathrm{C}$, (b) propionic acid, with filtration, $100^{\circ} \mathrm{C}$, (c) propionic acid, without filtration, $100^{\circ} \mathrm{C}$, (d) $n$-butylamine, with filtration, $200{ }^{\circ} \mathrm{C}$, and (e) $n$-butylamine, without filtration, $200^{\circ} \mathrm{C}$. 
peak at $80^{\circ} \mathrm{C}$, which was large at sample prepared with propionic acid and without filtration, was considered to be from the volatilization of water. Because this sample had large weight loss at $120^{\circ} \mathrm{C}$ in TG curve (Fig.3(c)). About other peaks in DTA curves, the reason was not clear. Samples prepared with $n$-butylamine indicated different DTA curves with the formers. Same tendency was observed in DTA curves of samples prepared with ethanol. The endothermic peaks were not large in sample prepared with propionic acid and without filtration.

\section{POWDER PROPERTIES OF PRECIPITATES}

For the application to catalyst and adsorbent, the powder properties of the obtained materials were evaluated. From SEM images, all samples had no specified particle shape in spite of added compound and heating temperature. FIGURE 5 shows particle size distribution of samples obtained in aqueous conditions. Samples prepared with propionic acid had smaller particles than sample prepared without additive. On the other hand, samples prepared with $n$-butylamine had larger ones. Same tendency was also observed in particle size distributions of samples prepared with ethanol.

TABLE 3 shows specific surface area of samples synthesized in various conditions. Specific surface area of samples prepared without additive had large specific surface area by heating. Samples prepared with propionic acid had smaller specific surface area than that without additives. On contrast, samples prepared with $n$-butylamine had large specific surface area. The filtration had less influence on specific surface area of phosphates.

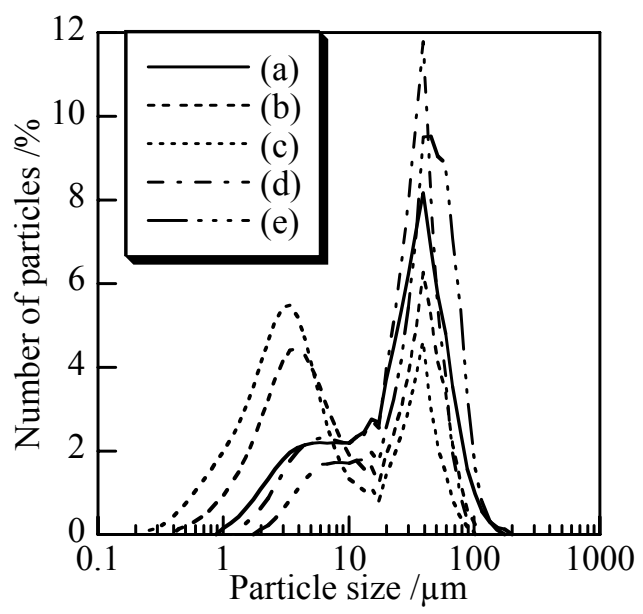

FIGURE 5. Particle size distribution of samples obtained in aqueous condition and at $200^{\circ} \mathrm{C}$, (a) no additive, (b) propionic acid, with filtration, (c) propionic acid, without filtration, (d) $n$-butylamine, with filtration, and (e) $n$-butylamine, without filtration.

\section{ADSORBENT FOR BASIC STINKING GAS}

Because phosphate materials are solid state acidic compounds, the adsorptive property of basic stinking gas was examined as one of applications ${ }^{14,15}$. TABLE 4 shows adsorption ratio of trimethylamine on samples prepared in various conditions. By the addition of propionic acid and $n$-butylamine, the adsorption ratio became larger. The maximum adsorption ratio was $51 \%$ in samples prepared with large amount of water ${ }^{13}$. Therefore, the preparation with small amount of solvent was suitable method to obtain functional phosphate materials.

TABLE 3 Specific surface area of samples synthesized in various conditions $/ \mathrm{m}^{2} \mathrm{~g}^{-1}$

\begin{tabular}{cccccccc}
\hline additive & filtration & \multicolumn{3}{c}{ water } & \multicolumn{3}{c}{ ethanol } \\
& & $100^{\circ} \mathrm{C}$ & $200^{\circ} \mathrm{C}$ & $400^{\circ} \mathrm{C}$ & $100^{\circ} \mathrm{C}$ & $200^{\circ} \mathrm{C}$ & $400^{\circ} \mathrm{C}$ \\
\hline non & - & 0.47 & 1.80 & 24.83 & 0.95 & 1.57 & 58.33 \\
propionic acid & $\circ$ & 1.79 & 2.57 & 24.14 & 1.54 & 3.07 & 22.29 \\
propionic acid & - & 2.08 & 3.09 & 18.29 & 2.64 & 2.94 & 22.62 \\
$n$-butylamine & 0 & $\mathrm{x}$ & 37.53 & 57.69 & $\mathrm{x}$ & 31.19 & 57.91 \\
$n$-butylamine & - & $\mathrm{x}$ & 37.63 & 55.01 & $\mathrm{x}$ & 52.34 & 68.70 \\
\hline
\end{tabular}

TABLE 4 Adsorption ratio of trimetylamine on samples $/ \%$

\begin{tabular}{cccccccc}
\hline additive & filtration & \multicolumn{3}{c}{ water } & \multicolumn{3}{c}{ ethanol } \\
& & $100^{\circ} \mathrm{C}$ & $200^{\circ} \mathrm{C}$ & $400^{\circ} \mathrm{C}$ & $100^{\circ} \mathrm{C}$ & $200^{\circ} \mathrm{C}$ & $400^{\circ} \mathrm{C}$ \\
\hline non & - & 33.8 & 7.0 & 0 & 0 & 0 & 44.4 \\
propionic acid & 0 & 0 & 61.5 & 16.7 & 0 & 34.8 & 40.1 \\
propionic acid & - & 0 & 35.9 & 50.8 & 0 & 51.9 & 69.0 \\
$n$-butylamine & - & $\mathrm{x}$ & 0 & 53.4 & $\mathrm{x}$ & 0 & 100 \\
$n$-butylamine & - & $\mathrm{x}$ & 0.2 & 100 & $\mathrm{x}$ & 4.1 & 84.0 \\
\hline
\end{tabular}




\section{CONCLUSION}

By the addition of propionic acid, the $\mathrm{Ce} / \mathrm{P}$ ratio increased in samples prepared with small amount of solvent. On the other hand, this ratio decreased in samples prepared with $n$-butylamine. This tendency was the reverse with phosphate materials prepared in large amount of water. XRD peaks of Monazite-type $\mathrm{CePO}_{4}$ were appeared by the addition of $n$-butylamine. The adsorption ratio of trimethylamine was high in samples prepared with small amount of solvent. The amount of solvent had much influence on the chemical composition, powder and acidic properties of phosphate materials.

\section{REFERENCES}

1. H. Onoda, H. Nariai, A. Moriwaki, H. Maki, I. Motooka, J. Mater. Chem., 12(6), 1754 (2002).

2. H. Onoda, T. Ohta, J. Tamaki, K. Kojima, Appl. Catal. A, 288(1-2), 98 (2005).

3. H. Onoda, T. Ohta, J. Tamaki, K. Kojima, H. Nariai, Mater. Chem. Phys., 96(1), 163 (2006).

4. M. Potoczek, A. Zima, Z. Paszkiewics, A. Slosarczyk, Ceram. Inter, 35(6), 2249 (2009).
5. C. Tas, Intern. J. Appl. Ceram. Tech., 4(2), 152 (2007).

6. S. Herasaki, F. Moztarzadeh, D. Sharifi, J. Biomed. Mater. Res., 83A(1), 80 (2007).

7. S. Herasaki, A. Zamanian, F. Moztarzadeh, J. Biomed. Mater. Res., 86B(1), 208 (2008).

8. H. Onoda, K. Taniguchi, I. Tanaka, Microp. Mesop. Mater., 109(1-3), 193 (2008).

9. H. Onoda, S. Ukita, A. Hayashi, A. Takenaka, K. Kojima, Phosphorus Res. Bull., 19, 209 (2005).

10. H. Onoda, Y. Fukumura, A. Takenaka, J. Mater. Sci. Eng. Adv. Tech., 1(1), 97 (2010).

11. H. Onoda, Y. Ishima, A. Takenaka, I. Tanaka, Mater. Res. Bull., 44, 1712 (2009).

12. K. Binnemans, Handb. Phys. Chem. Rare Earths, 36, 281 (2006).

13. H. Onoda, A. Ikawa, J. Therm. Anal. Calor., submitted.

14. T. Hu, G. Zeng, D. Huang, H. Yu, X. Jiang, F. Dai, G. Huang, J. Hazard. Mater., 141(3), 736 (2007).

15. N. Burka, A. Assabbane, A. Nounah, L. Laanab, Y. Ichou, Desal., 235(1-3), 264 (2009). 